ISSN 1112-9867

Available online at

http://www.jfas.info

\title{
DAILY RAINFALL-RUNOFF MODELLING BY NEURAL NETWORKS IN SEMI-ARID ZONE: Case of Wadi Ouahrane's basin
}

\author{
K. Benzineb* ${ }^{1}$, M. Remaoun ${ }^{2}$ \\ ${ }^{1}$ Laboratory for plant chemistry-water-energy, University Hassiba Ben Bouali Chlef, Algeria \\ ${ }^{2}$ Laboratory for plant chemistry-water-energy, University Hassiba Ben Bouali Chlef, Algeria \\ Received: 05 June 2016 / Accepted: 25 August 2016 / Published online: 01 September 2016
}

\begin{abstract}
This research work will allow checking efficiency of formal neural networks for flows' modelling of wadi Ouahrane's basin from rainfall-runoff relation which is non-linear. Two models of neural networks were optimized through supervised learning and compared in order to achieve this goal, the first model with input rain, and the second one with rain and input ETP. These neuronal models were compared with another overall model, the GR $4 \mathrm{j}$ model. Then, it has been optimized and compared with the three first models, a third model of neural network with rain, ETP and soil moisture (calculated by the model GR4j) input.

The neuronal models were optimized with algorithm of Levenberg Marquarld (LM), while the GR4j model was optimized with SCE-UA method. The Nash criterion (\%) and the correlation coefficient of Pearson (R) allowed appreciating performances of these models.
\end{abstract}

Keywords: modeling; neural network; supervised learning; algorithm of Levenberg Marquarld; GR4J.

Author Correspondence, e-mail: benzineb_kh@ outlook.fr

doi: http://dx.doi.org/10.4314/jfas.v8i3.17

\section{INTRODUCTION}

The hydrologic behaviour modelling of watersheds is imperative since one is interested to 
problems related to floods disasters; these exceptional hydrologic events constitute one of the major natural risks sometimes responsible of human lives' loss and material goods. In order to face inundations risks caused by floods, the decision-makers are requiring tools allowing them to be in a better position to manage this crisis situation. We need to have reliable tools to be able to take the necessary steps in order to mitigate the potential damage. In this case, the rainfall-runoff's model finds its need where the model designed from rain chronicles observed, can generate flows which would be as close as possible of observed flows, namely, from observations of rain fell, we are able to reproduce (or to forecast) the response in basin flow.

The non-linearity of the rainfall-runoff relation often complicates the hydrologist's task in their need to model flows to the outlet of a stream. Also, identification of all processes involved on the watershed and their integration in a modelling process leads to complex models using a higher parameters number. The use of models with low variables number, able to treat the non-linearity is thus essential. These last years, with appearance of learning algorithm by weight adaptation and facing the non-linearity relation of rainfall-runoff, researches deepened towards new approaches non-determinists, as illustrate the artificial neural networks. They opened the voice to a category of rainfall-runoff models based on the artificial intelligence [1, 2].

In this field, works of several authors show that these models inspired of biological neurons functioning, are very performing for simulation and flows forecasting on the watersheds. Several studies conducted in America [3], in Europe [4, 5], in Africa [6] and in Algeria [7, 8] confirm the best simulation results and forecasting with neural networks. This research work will allow checking efficiency of formal neural networks for flows simulation in semi-arid zone (case of Oued Ouahrane's basin). In fact, this study will allow optimizing and comparing neuronal models and a global conceptual model (GR4J) for floods flow simulation of wadi Ouahrane's basin. To achieve this goal, this article begins by a presentation of the study area, then the chapter "material and methods" where are presented data and so their pre-treatments, design of different models and performance criteria which will allow appreciating the developed models. The results and their discussion will end this work.

\subsection{PRESENTATION OF THE STUDY AREA}


The sub-watershed of wadi Ouahrane purpose of this study spreads on $270.15 \mathrm{~km}^{2}$ to South of Ténès and located on the North of the entire river basin Cheliff-Zahraz. This basin is limited on the North by wadi Allalla's basin, on the South by wadi Sly's basin, on the East by wadi Fodda's basin and on the West by wadi Ras's basin (Figure 1).

The basin's study is a rather elongated form in the axis of the main stream and oriented to North-North-West. Figure 1 represents wadi Ouahrane as a tributary of wadi Cheliff with an outlet located at $13 \mathrm{~km}$ to the North-West of Chlef town.

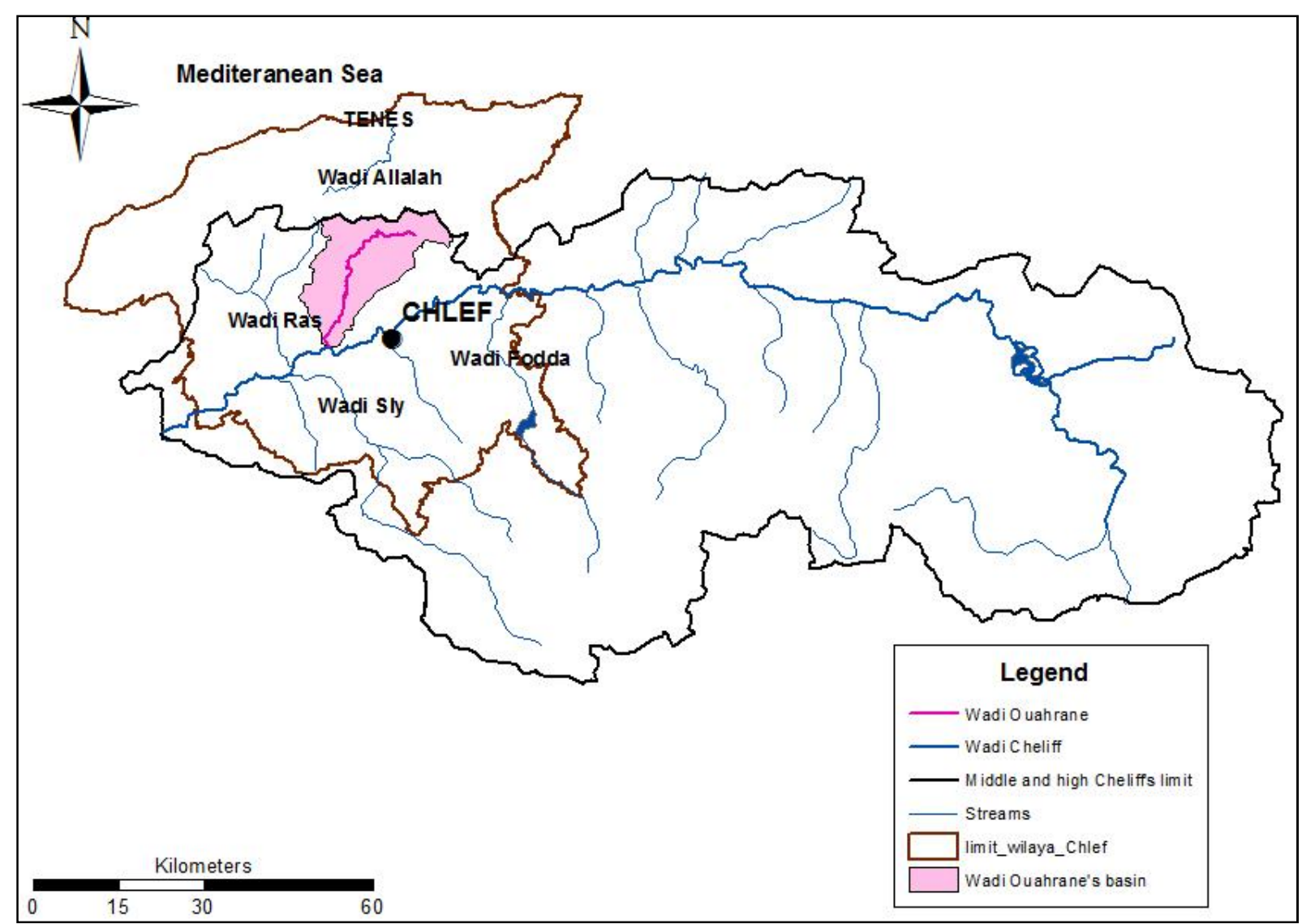

Fig.1. Location of wadi Ouahrane's basin in the middle and the high Cheliff's basin

\subsection{Presentation and treatment of hydro climatic data}

The watershed of wadi Ouahrane belongs to semi-arid medium tempered bio climate. The average annual temperature is $18.7^{\circ} \mathrm{c}$. The average inter-annual rainfall is $571 \mathrm{~mm}$. The relative humidity is $64 \%$. This basin is checked by three rainfall posts and a gauging station (Larabaâ Ouled Farès). Stations of Larabaa Ouled Fares and of Benairia were operational from the first half of years 1970 and the post of Bouzghaia started late from 1995. As a result, in view of a 
best statistical processing of rain data, we have considered only the posts of Benairia and of Larabaâ Ouled Fares.

The present works build on an important database (rain, ETP and flow) covering the whole study area. They were gathered from National Agency of Water Resources (NAWR) of Blida and National Office of Meteorology (NOM) Chlef. The rainfall data series made at our disposal (1983/84 - 2011/12) present some gaps. In the aim to have continuous data set, rainfall data of Benairia station were compared to the database of Larabaa Ouled Fares's station, selected as reference station. From this comparison, it emerges that rains of both stations are correlated at $85 \%$ (Figure 2).

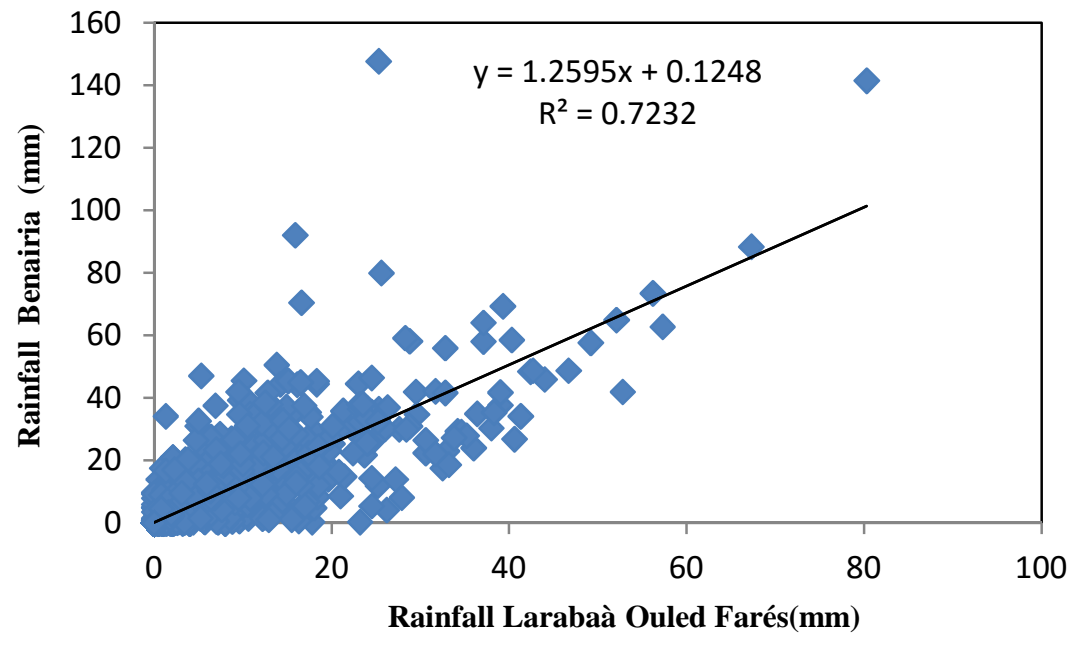

Fig.2. Correlation rain Larabaà Ouled Farès and rain Benairia

As for the flow data, we have a series of 29 years (1983/84 to 2011/12), The lags have been filled with method of analogue proportionality.

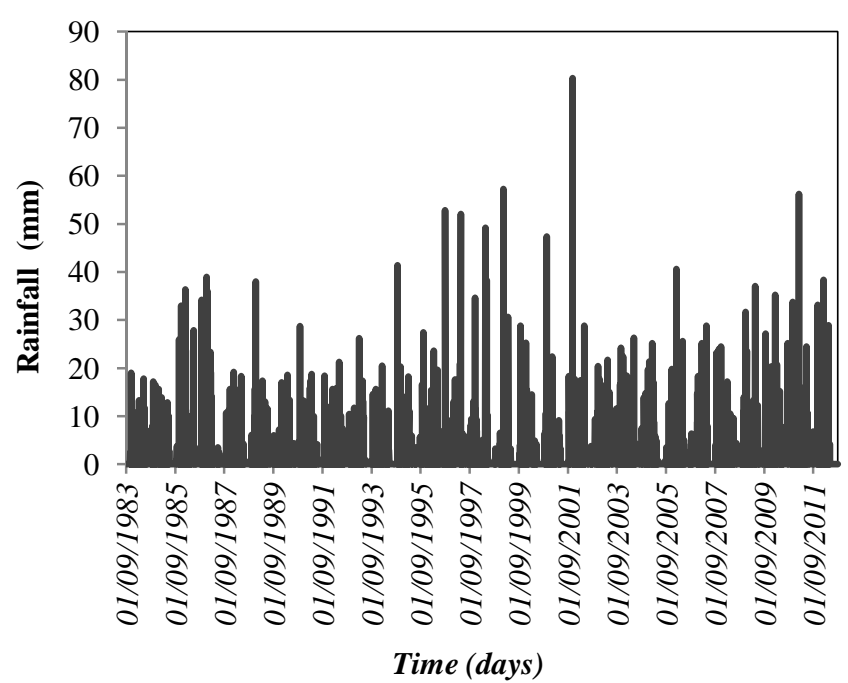

(a)

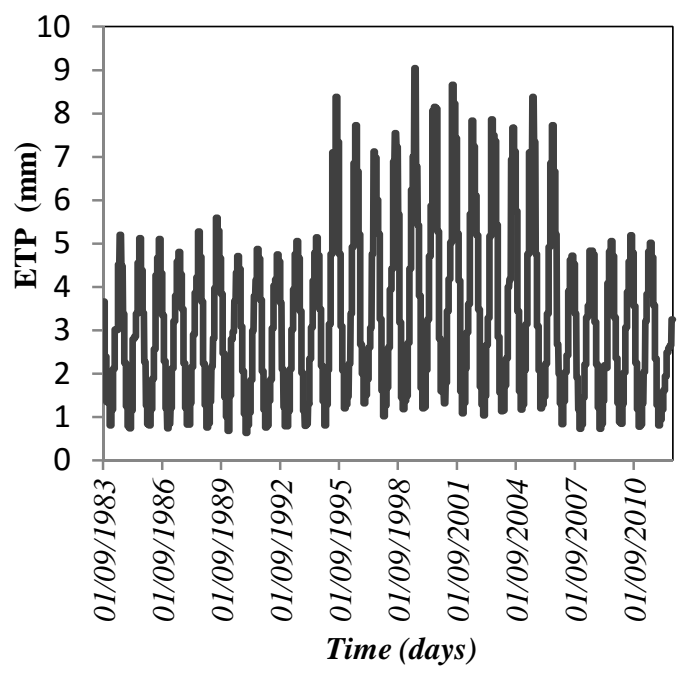

(b) 


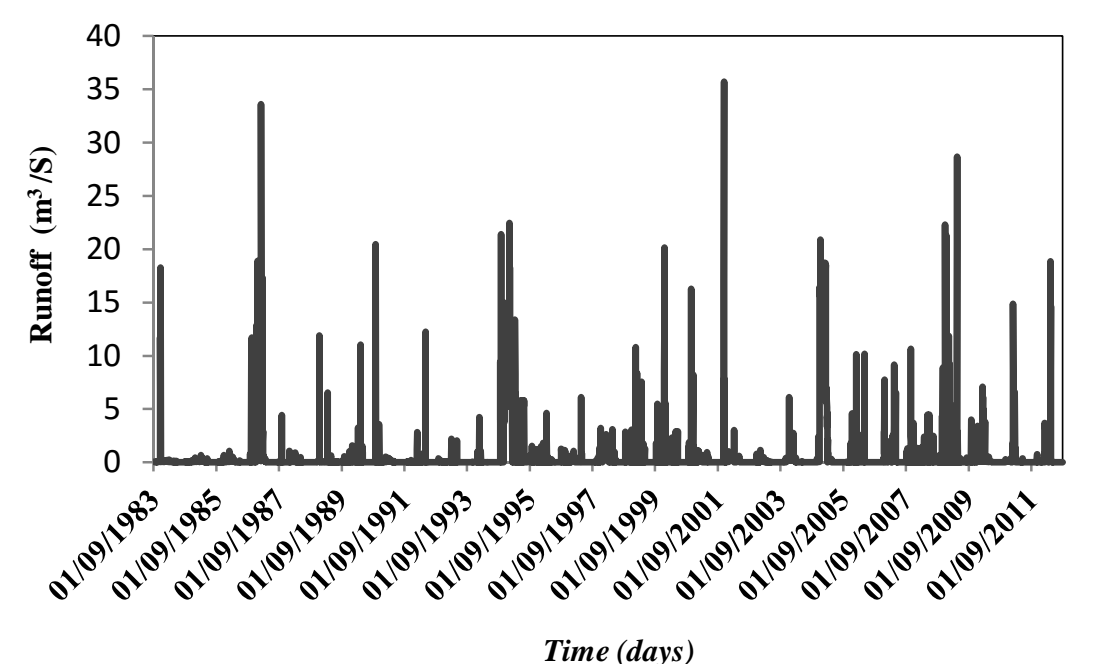

(c)

Fig.3. Evolution of hydrometeorological variables, (a) rainfall, (b) runoff, (c) Evapotranspiration.

\subsection{MODELES PRESENTATION}

\subsubsection{Neural networks}

From 1997, several hundred of articles had been published on neural networks application to the water resource management. The half of hydrology applications of these models concern rainfall-runoff relation with works of several authors $[9,10,11,7,12,3,13,6]$.

\section{Generalities on neural networks}

The neural networks are composed of simple items (or neurons) functioning in parallel. These items have been strongly inspired by biologic nervous system [14, 15]. As in the nature, functioning of network (neural) is strongly influenced by items connections between them. Similarities have, therefore, been established between biological neurons items and components of Formal Neurons or Artificial (Figure 4).

There are several designs of neural networks [16]. But, the multilayer perceptron, which is an extension of Monolayer Perceptron, with one or several hidden layers between input and output, is used in this study. 

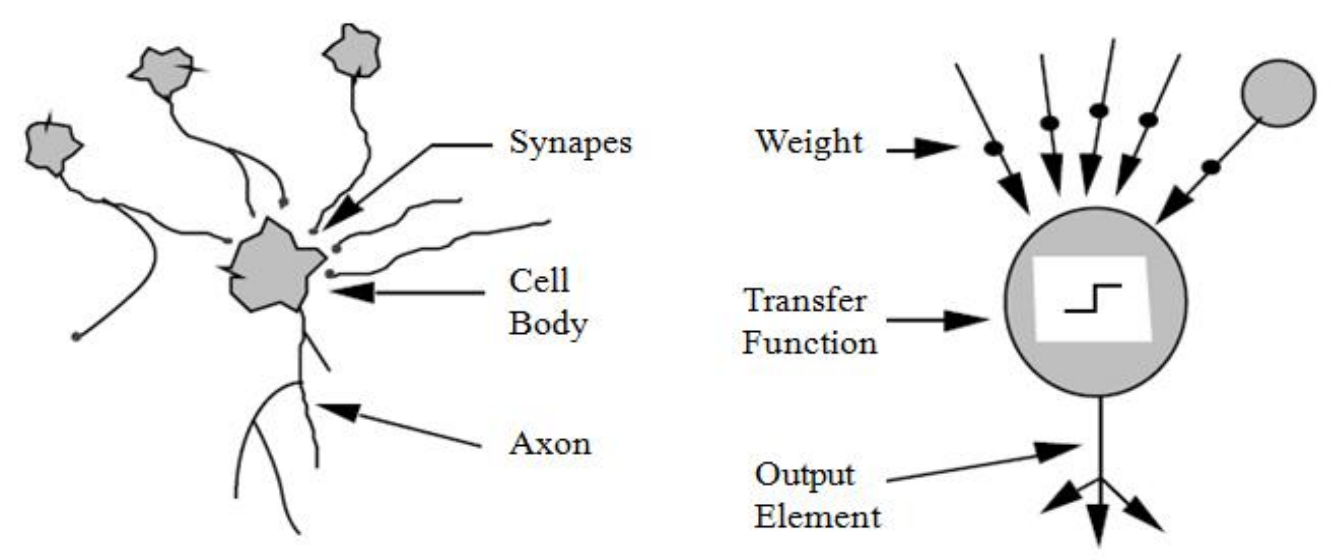

Fig.4. Analogy between biological and artificial neuron [16]

\section{Multilayer's Perceptron}

Computerized capacities have strongly progressed in the beginning of 1980, researches were resumed. So, Rumelhart, Hinton and Williams developed an ANN called Mutil-Layered Perceptron (MLP) with a learning algorithm called back propagation [17].

A multi-layers neural network is formed of an assembly of elements (neurons), each one is linked to other neurons. Those are positioned in a series of layers: the first layer (input layer), the (second) layer (s) intermediate (called hidden layers), and the last called output layer. Figure 5 presents a MLP to a hidden layer.

Each connexion point (called coefficient or weight) between two neurons plays a role of synapse, the main interaction element between neurons. These connexions or synaptic weight have a seminal role in parallel and adaptive functioning of neurons. The neurons of hidden layers change the inputs and outputs and this in two stages:

- The neuron calculates first its potential: each input is multiplied by its corresponding weight.

- Neuron's Input is changed in output (simulated flow): Each neuron receives inputs under vector form $(X)$, performs a weighted sum $(\alpha)$, and generates with the help of transfer function $(\mathrm{G})$ a real result $(\mathrm{Y})$

$\mathrm{W}=\left(\mathrm{w}_{\mathrm{i} 1}, \mathrm{w}_{\mathrm{i} 2} \ldots, \mathrm{w}_{\mathrm{in}}\right)$ represents the neuron weights (or weights matrix); $\mathrm{X}=\left(\mathrm{x}_{\mathrm{i} 1}, \mathrm{x}_{\mathrm{i} 2} \ldots, \mathrm{x}_{\mathrm{in}}\right)$ are neuron s'inputs $\mathrm{i}$ (or input vector), $\mathrm{b}$ is the bias of the neuron or threshold value. 
The activation function generally classical non-linear is the sigmoid function. It represents a benefit to be regular, monotone, continuously differentiable, and limited between 0 and 1 :

$$
G(\alpha)=\frac{1}{\left(1+e^{-\alpha}\right)}
$$

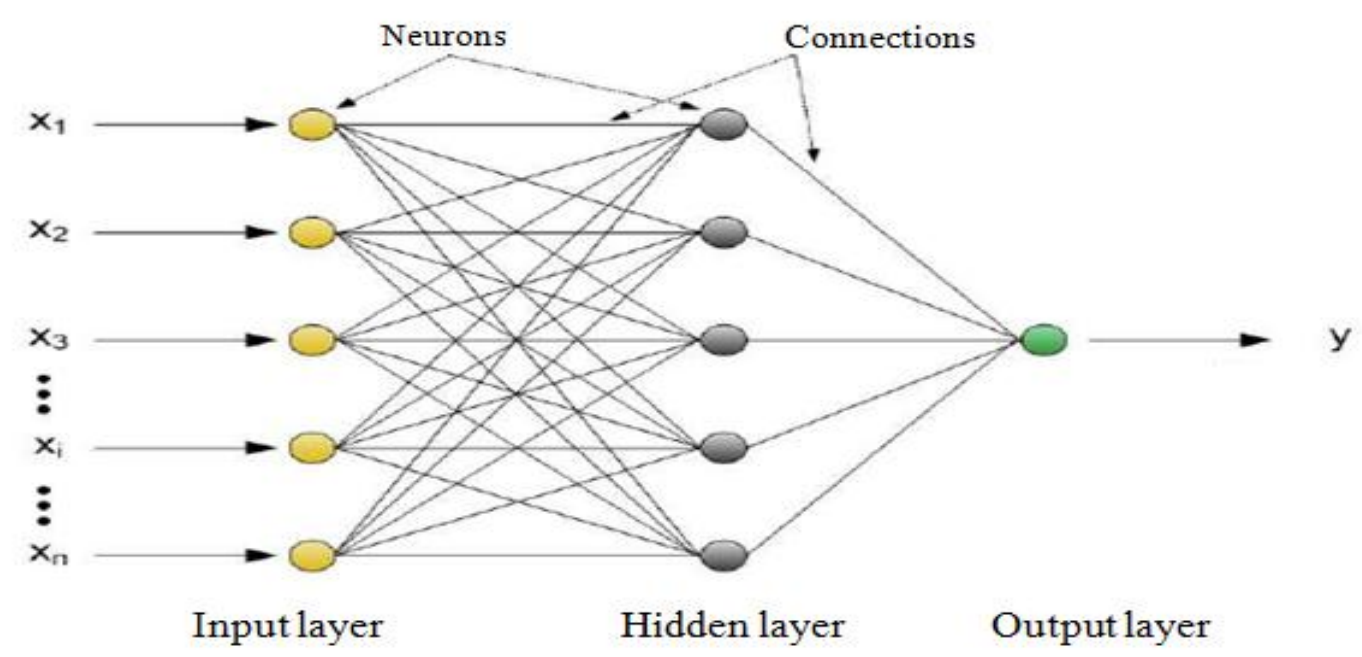

Fig.5. Représentation of a multi-layer artificial neural network

\section{Learning of neural networks}

The development's crucial point of neural network is its learning. It is about an adaptive procedure by which neurons connexions are fitted in front of information source $[17,18]$.

In the case of artificial neural networks, we often add to the model description the learning algorithm. In the majority of actual algorithms, modified variables during learning are the connexions' weights. The learning is the change of network weights in a view to allow response to examples' network and to the experience. There are several learning rules which can be gathered in three categories:

- Supervised learning (or from examples) combines a specific response to each input signal. The procedure is being introduced gradually until the error between network outputs and desired results (data observed) are minimized.

- Non-supervised learning: it comprises adjusting weights from a single training set formed only of data, no desired result has been provided to the network.

- Enhanced learning: represents a new technique that shares with supervised learning, the presence of a supervisor regulated by a performance degree measure (a rank or point) who considers learning evolution of the network after some iterations, and similarity 
with a non supervised learning, since it necessitates only inputs variables, without defining variable to the network input.

\section{Characteristics of used models}

With a view to verifying these models performance on the watershed of wadi Ouahrane, it has been optimized and compared, in this work, two architectures series (a first series with input rain) (model N 1) and a second with rain and input ETP (model N2).

Different weights (parameters) of neuronal models have been fitted by applying the supervised learning as a whole with Levenberg Marquartd (LM) algorithm.

Various designs proposed are results of several optimisation phases having allowed selecting the best models (table 1).

Table1. The best neural networks designs selected

\begin{tabular}{cccc}
\hline Models & Variables & Neurons number on hidden layer & Architecture \\
\hline $\boldsymbol{N 1}$ & Rain & 4 & 141 \\
\hline $\boldsymbol{N} 2$ & Rain & 4 & 241 \\
& ETP & & \\
\hline
\end{tabular}

\subsection{2. $G R 4 j$}

The GR4j Model (model of the Rural Engineering at 4 daily parameters) has been used as reference model in this study. It is a global rainfall-runoff model with four parameters.

This model experienced several versions, successively proposed by [19, 20, 21, 22, 23 and 24], who allowed improving progressively the model performances. It is version of [24], represented in figure 6 , and over its structure lets appearing conceptual tank models, with a monitoring process of basin's moisture state allowing giving to the model an anterior conditions memory and to ensure a continuous functioning. Its structure associates a production tank and a routing tank, unitary hydrographs and so other functions allowing simulating the hydrological behaviour of the basin. 


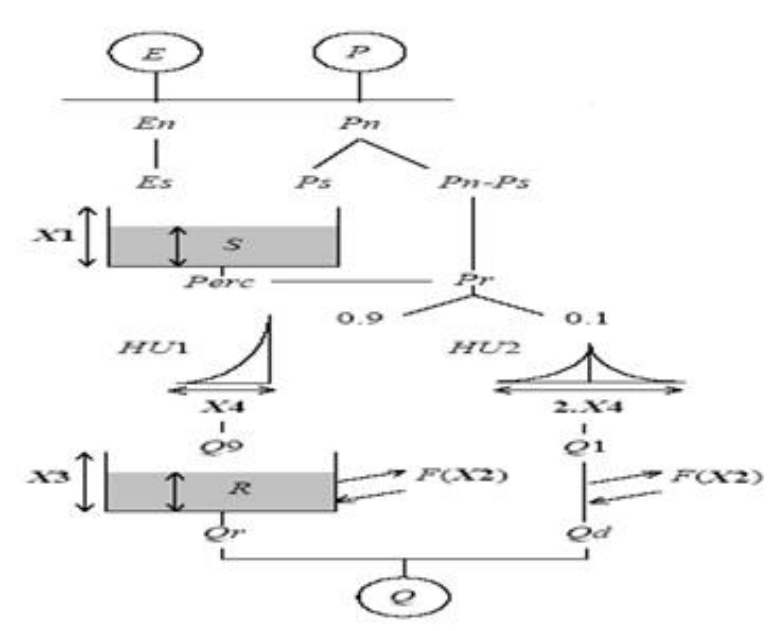

Fig.6. General structure of the model GR4j [24].

\subsubsection{Performances criteria}

The used performances criteria concerning this study are: Nash's criterion and Pearson correlation coefficient. Nash's criterion introduced by [25], it is defined:

$$
N a s h=(100) \times\left(1-\frac{\sum_{i=1}^{n}(T i-P i)^{2}}{\sum_{i=1}^{n}(T i-\bar{P})^{2}}\right)
$$

Ti and Pi respectively the measured flows (observed) and calculated for $\mathrm{i}=1, \ldots, \mathrm{N}, \bar{P}$ is the average of the calculated flows.

Nash criterion can be interpreted as being the variance proportion of the observed flow explained by the model. If Nash $=100 \%$ adjustment is perfect, but if Nash $<0$, the flow calculated by the model is the misestimate than the simple average flow.

As for Pearson correlation coefficient, it is usually used to evaluate performance of hydrogeological and hydrological models [26]. It is obtained by calculating linear regression between calculated (flows) values and values (flows) observed or measured. Its formula is given by equation 3 .

$$
R=\frac{\sum_{i=1}^{N} t_{i} P_{i}}{\sqrt{\left(\sum_{i=1}^{N} t_{i}^{2}\right)} \sqrt{\left(\sum_{i=1}^{N} P_{i}^{2}\right)}}
$$


Ti and Pi respectively measured flows (observed) and calculated for the $\mathrm{i}=1, \ldots, \mathrm{N}, \bar{T}$ and $\bar{P}$ are respective averages of flows observed and calculated. $\mathrm{N}$, inputs number $t_{i}=T_{i}-\bar{T}$, $p_{i}=P_{i}-\bar{P}$. The correlation between flows observed and calculated flows [26] is:

Perfect if $\mathrm{R}=1$, very strong if $\mathrm{R}>0,8$, strong if $\mathrm{R}$ is between 0,5 and 0,8 , average intensity if $\mathrm{R}$ is between 0,2 and 0,5 , low if $\mathrm{R}$ is between 0 and 0,2 , nul if $\mathrm{R}=0$.

\section{RESULTS AND DISCUSSION}

In order to better appreciate performance and robustness of the developed models, and so their predictive power, we present at a time results observed during calibration phases and validation. The calibration process has been made on a period of 02 years (1998-2000). As for validation, we used new database corresponding to period (2007-2009).

The calibration and validation results of Larabaa Ouled Farès station are represented in table 2. According to table 2 it can be seen that: results obtained with different developed models (neuronal models) (N 1 and $\mathrm{N} 2$ ) and model (GR4j) are generally very satisfactory in calibration with Nash's criteria which are above $74 \%$ and correlation coefficient of Pearson vary from strong to very strong between 0,66 and 0,92 in calibration and in validation.

Table2. Neuronal models performance (N 1, N 2) and GR4j model at study s' station

\begin{tabular}{cccccc}
\hline & \multicolumn{2}{c}{ Calibration } & \multicolumn{2}{c}{ Validation } \\
\hline Station & Modèle & Nash $(\%)$ & $\mathrm{R}$ & Nash (\%) & $\mathrm{R}$ \\
\hline \multirow{3}{*}{$\begin{array}{c}\text { Larabaà Ouled } \\
\text { Fares }\end{array}$} & $\mathbf{N ~ 1}$ & 74,66 & 0,857 & 53,26 & 0,66 \\
\cline { 2 - 6 } & $\mathbf{N ~ 2}$ & 84,79 & 0,920 & 64,17 & 0,737 \\
\hline
\end{tabular}

Adding potential evapo-transpiration improves performance of neural networks as much in calibration as in validation. A comparison done between neuronal models 'performances (N1 and N2) and GR4j model shows that neuronal model (N2) is more efficient than GR4 $\mathrm{j}$ model as much in calibration as in validation. Figure 7 represents hydrographs measured and calculated respectively for neuronal models $\mathrm{N} 1, \mathrm{~N} 2$ and GR4j model at station of Larabaà Ouled Farès.The table 2 and analysis of figure 7 allow noting that neural networks with rain input only are less efficient than GR4j model. In contrast, adding potential evapo-transpiration improves a little bit the performance of neural network, Neural model (N2) appears more efficient that 
GR4j model. Works of [27], showed that ETP influences more the daily oscillations of a river flow than the ground waters that come out from the watershed considered.
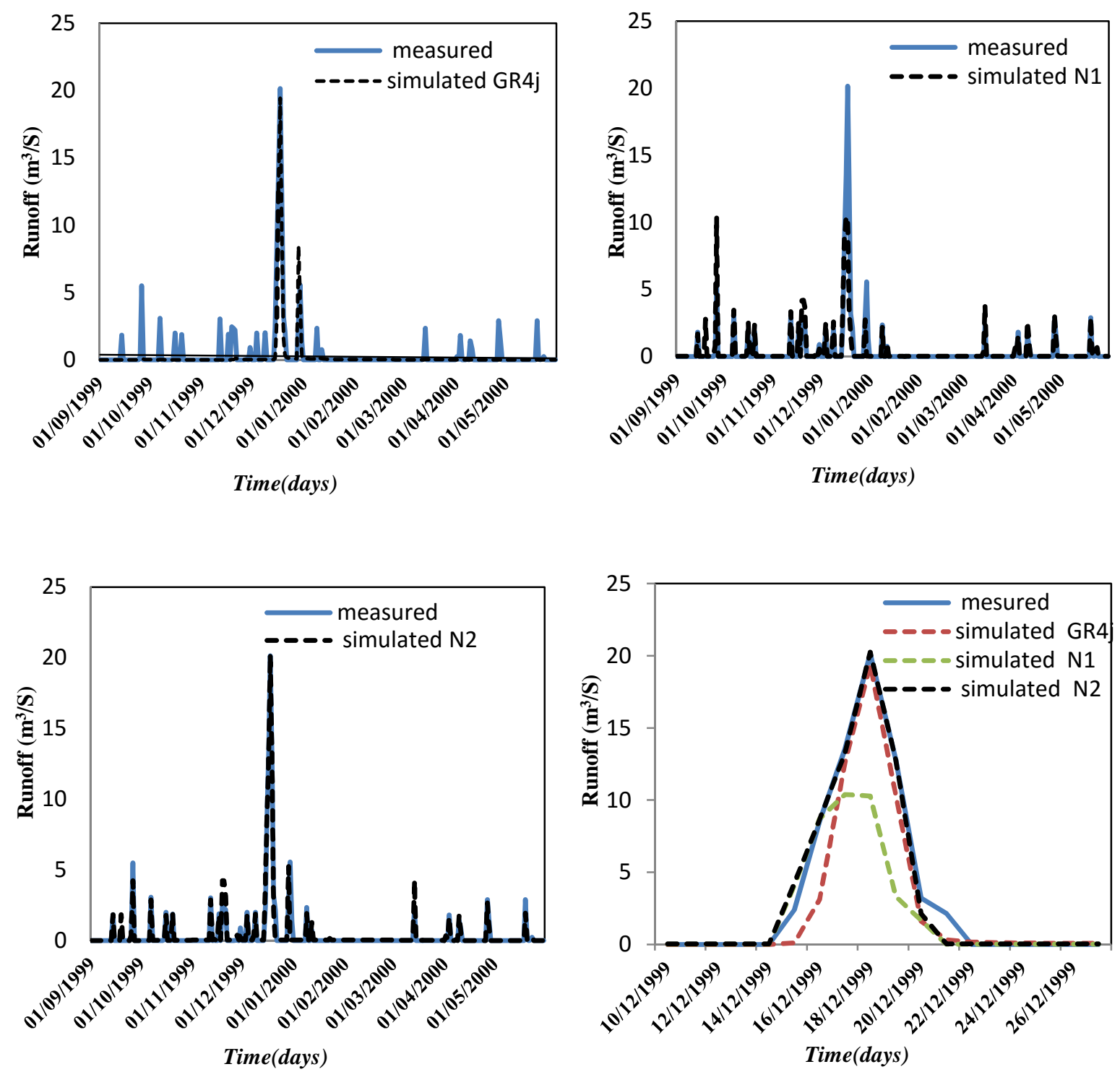

Fig.7. Evolution of measured and calculated hydrographs by GR4j models and neural models to Larabaà Ouled Fares station during calibration

\section{Neural network with three inputs (N3)}

The prior results showed the need to improve neuronal models performances. For this purpose, we decided to introduce a third input. The soil tank moisture level: simulated by GR $4 \mathrm{j}$ model, it represents a vital resource for directing neural networks. The N3 model (neural network with three inputs: rain, ETP and soil moisture) is optimized and compared with other models (N1, $\mathrm{N} 2$ and GR4j). 
The design of this model (N3) is set after several optimization phases (multi-layers perceptron to a hidden layer with five neurons on the hidden layer). The results presented in Table 3 show a significant improvement of neural networks performances with three inputs. In fact, for calibration phases, we obtain a high Nash's criterion value (>90\%), results obtained in validation phase are acceptable. This expresses the correct model's functioning and the judicious choice of the third decisive input for the model's direction.

The same studies [28] showed that, as much input data of neural networks are numerous, as models are efficient.

Table3. Neural network performances with three inputs (N3) at station of Larabaâ Ouled Farès

\begin{tabular}{ccc}
\hline & Nash (\%) & $\mathbf{R}$ \\
\hline Calibration & 91,69 & 0,955 \\
\hline Validation & 70,80 & 0,826 \\
\hline
\end{tabular}

In figure 8 , we note a good hydrographs production by neuronal model (N3). The hydrographs observed and calculated are in fact very synchronous there where appear the floods. For all simulated series, flows are reproduced on a regular basis, with a good peaks flows simulation.
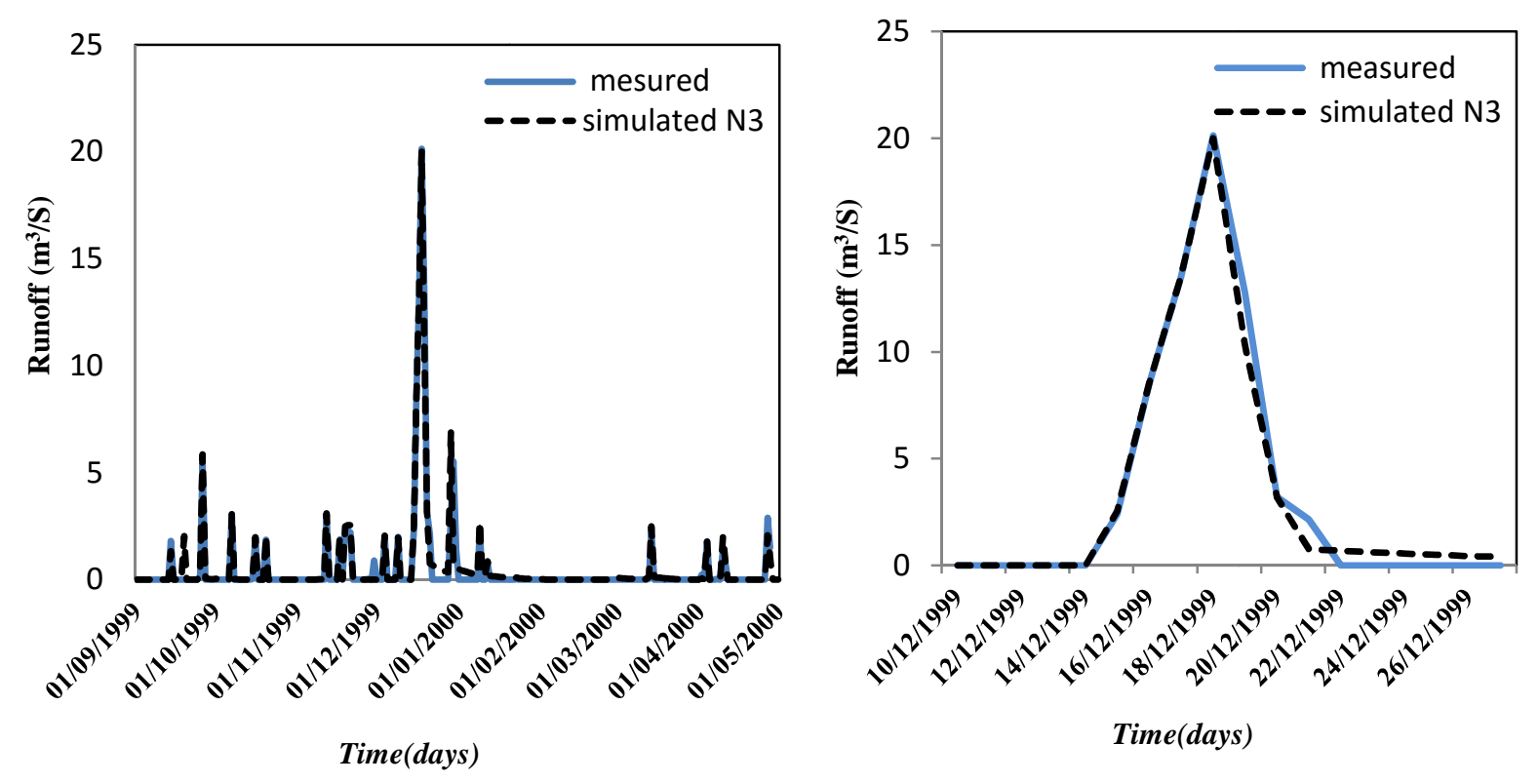

Fig.8. Evolution of measured and calculated hydrographs by the model N3 to Larabaà Ouled Fares station during calibration 


\section{CONCLUSION}

Our study aimed to explore neural networks performances (black box model). In fact, these models have been optimized and compared with another model type GR4j (tank conceptual model). Neural networks (N1) with a single input (rain) are less efficient that model GR4j. In contrast, the addition of evapo-transpiration (ETP) as explicative variable at the input of neuronal models developed (N2) has strongly improved their performances. In fact, neuronal model (N2) is more efficient than GR4j model as much in calibration as in validation.

Given the complexity of rainfall-runoff relation at daily time step, improvement of neural network is essential. So, the introduction of a third input (simulated soil moisture by GR4j model) seems to be necessary to optimize this model. The neuronal model (N3) with three inputs (rain, ETP and soil moisture) tested in basin of wadi Ouahrane gave the best results than those obtained by other models. This model allows a best reproduction of maximum flows and simulates flows quite correctly, even in validation Combination of two approaches, conceptual and black box therefore, seems to be imperative to improve quality of rainfall-runoff modelling to the daily time step.

\section{REFERENCES}

[1] French M, Krajewski W, and Cuykendall R. Rainfall forecasting in space and time using neural network. J. Hydrol., 1992, 137, 1-31.

[2] Minns A, Hall J. Artificial neural network as rainfall-runoff models. Hydrol. Sc. J., 1996, 41(3), 399-417.

[3] Wenri H, Xu B, and Amy C. Forecasting flows in Apalachicola River using neural networks. Hydrological Processes, Vol. 18., 2004, 2545-2564.

[4] Johannet A, Ayral P, and Vayssade B. Modelling non measurable processes by neural networks: forecasting underground's flow. International Joint Conferences on Computer, Information and Systems Sciences and Engineering., 2006, 6, 4-14.

[5] Ayral P. Contribution à la spatialisation du modèle de prévision des crues éclaires ALHTAIR. Approche spatiale et expérimentale, application au bassin versant du Gardon d'Anduze. Thèse de Doctorat, Université de provence, Aix-Marseille 1, LGEI, Ecole des 
Mines d'Alès, Alès, France, 2005, pp.311

[6] Koffi Y, Ayral P, Kouassi A, Johannet A, et Biemi J. Modélisation des débits des rivières en région tropicale humide : application des réseaux de neurones et du modèle GR2M au Bandama Blanc (CÔTE D’IVOIRE). Rev. Ivoir. Sci. Technol., 2011, 17, 151-171

[7] Dechemi N, Tarik B, et Issolah A. Modélisation des débits mensuels par les modèles conceptuels et les systèmes neuro-flous. Revue des Sciences de 1'Eau. Vol. 16 nº4., 2003, 407-424.

[8] Tarik B, Dechemi N. Daily rainfall-runoff modelling using conceptual and black box models; testing a neuro-fuzzy model». Journal des Sciences Hydrologiques, Vol. 49., 2004 , 919-930.

[9] Dimopoulos L, Leck S, et Lauga J. Modélisation de la rélation pluie-débit par les réseaux connexionnistes et le filtre de Kalman. Journal des Sciences Hydrologiques, Vol. 41, $\mathrm{n}^{\circ} 2$, 1996, 179-193.

[10] Abrahart R, See L. Comparing neural network and autoregressive moving average techniques for the prevision of continuous river flow forecasts in two contrsting catchments. Hydrological Processes, Vol. 14., 2000, 2157-2172.

[11] Schumann A, Funke R, and Schulz G. Application of a geographic information system for conceptual rainfall-runoff modelling. Journal of Hydrology, Vol. 240., 2000, 45-61.

[12] Li-chiu C, John C, and Yen-ming C. A two-step-ahead recurrent neural network for stream-flow forecasting. Hydrological Processes, Vol. 18., 2004, 81-92.

[13] Ashu J, Sudheer K, and Sanaga S. Identification of physical processes inherent in artificial neural network rainfall-runof models. Hydrological processes, Vol 18., 2004, 571-581

[14] Coulibaly P, Anctil F, and Bobee B .Prévision hydrologique par réseaux de neurones artificiels : Etat de l'art. Revue canadienne de génie civil, Vol. 26., 1999, 293-304

[15] Werbos P. Applications of advances in nonlinear sensitivity analysis. System modeling and optimization. Drenick R. et Kozin F. Springer-Verlag, New York., 1981, 762-770.

[16] Touzet C. Les réseaux de neurones artificiels. Introduction au connexionnisme.Cours, exercice et travaux pratiques, 1992 , pp 58 
[17] Rumelhart D, Hinton G, and Williams R. Learning internal representations by error propagation, Parallel Distributed Processing, Vol. 1, MIT Press., 1986, pp. 318-362

[18] Hebb D, The organisation of behavior, Wiley, New-york, 1949.

[19] EdijatnO, Nascimento N, Yang X, Makhlouf Z, and Michel C. GR3J: a daily watershed model with three free parameters. Hydrological Sciences Journal ., 1999, 44(2), 263-277.

[20] EdijatnO, Michel C. Un modèle pluie-débit journalier à trois paramètres. La Houille Blanche, $n^{\circ} 2 ., 1989,113-121$.

[21] Nascimento N. Appréciation à l'aide d'un modèle empirique des effets d'action anthropiques sur la relation pluie-débit à l'échelle du bassin versant. Thèse de Doctorat, CERGRENE/ENPC, Paris, 1995, p550 .

[22] EdijatnO. Mise au point d'un modèle élémentaire pluie-débit au pas de temps journalier. Thèse de Doctorat, Université Louis Pasteur/ENGEES, Strasbourg, 1991, p 242 .

[23] Perrin C.Vers une amélioration d'un modèle global pluie-débit au travers d'une approche comparatif docteur de institut national polytechnique de Grenoble L' INPG, 2000, p527.

[24] Perrin C, Claude M, and Vazken A. Improvement of a parsimonious model for stream flow simulation, journal hydrologique., 2003, 279, pp 275-289.

[25] Nash J, Stucliffe J. River flow forecasting through conceptual models. Part 1. A discussion of principles. Journal of Hydrology, Vol. 10., 1970, 282-290.

[26] Legates X, Mccabe J. Evaluating the use of "goodness-of-fit" measures in hydrologic and hydroclimatic model validation. Water Resources Research, Vol. 35, n¹., 1999, 233-241

[27] Callede J. Oscillation journalière du débit des rivières en absence de précipitation. Cah. ORTOM, Sér., Hydrol., vol. XIV, n³., 1977, 219-283

[28] Rija N, Lauret P, Randriamanantany Z, et Gatina J. Modélisation du régime annuel des petites rivières en vue d'installation de microcentrales hydroélectriques. Afrique Science., 2009, 05(1), 39- 49

\section{How to cite this article:}

Benzineb K, and Remaoun M. Daily rainfall-runoff modelling by neural networks in semi-arid zone: Case of wadi Ouahrane's basin. J. Fundam. Appl. Sci., 2016, 8(3), 956-970. 